\title{
Cenas do rádio em Los Diarios de Emilio Renzi e em Black out ${ }^{l}$
}

Miriam Viviana Gárate

Recebido em: 2 de setembro de 2018 Aceito em: 22 de outubro de 2018
Miriam V. Gárate é Mestre e Doutora em Letras pela Universidade Estadual de Campinas, onde atua como docente no Departamento de Teoria Literária. Autora do livro Entre a letra e a tela. Literatura, imprensa e cinema na América Latina (2017) e dos capítulos Lecturas/escrituras "fuera de lugar" (pero no de cualquier sitio). A propósito de dos textos de Juan Villoro (2018) e Notas de trabalho: a propósito de Los diarios de Emilio Renzi (2019), dentre outros

Contato: miriam_sarate@ yahoo.com. br Brasil 


\section{PALAVRAS-CHAVE:}

Literatura e experiência;

Ricardo Piglia; María

Moreno.

KEYWORDS: Literature and experience; Ricardo Piglia; María Moreno.
Resumo: $\bigcirc$ artigo propõe um diálogo entre Los diarios de Emilio Renzi, de Ricardo Piglia (2015, 2016, 2017), e Black out, de María Moreno (2016a), a partir da leitura de alguns fragmentos nos quais se põe em cena uma "imaginação intimista" (Link, 2007) ou, recorrendo às palavras de Renzi em seu diário, a "pré-história de uma imaginação pessoal". A evocação de escutar rádio nos dias de infância e juventude, comum aos narradores de ambos os livros, remete a uma experiência vital, a um imaginário de época e à genealogia de uma poética que busca equacionar registros verbais e gêneros discursivos heterogêneos, e abrir-se à experimentação e à "escuta das reverberações do mundo", como cita Horacio González (2017), na escrita.

Abstract: This article proposes a dialogue between Los diarios de Emilio Renzi, by Ricardo Piglia (2015, 2016, 2017), and Black out, by Maria Moreno (2016a), according to reading of fragments that evidence an "intimate imagination" or, as Renzi states in his diary, the "prehistory of a personal imagination". The mention to listening to the radio during childhood and youth, common to the narrators of both books, refers simultaneously to a vital experience, to the imaginary of its time and to a poetry genealogy that seeks to combine different verbal levels and discursive genres, experimenting and "listening to the reverberations of the world" in writing, as stated by González (2017). 
A possibilidade de um diálogo entre Los diarios de Emilio Renzi (Piglia, 2015, 2016, 2017) e Black out (Moreno, 2016a) foi mencionada por alguns críticos e pela própria autora desse "romance, memória, retrato de época, microensaio, crônica social, diário íntimo, registro científico, desnudo, crítica, mapa" na contracapa da obra, não por acaso dedicada a Beba Eguía e Ricardo Piglia. ${ }^{2}$ Em ambos os casos, blocos de vida de uma "tribo" que, nas décadas de 1960 e 1970, circulava pelos bares de Buenos Aires e nesses espaços de leituras, paixões e debates, vão delineando uma cartografia que possui pontos em comum, embora também traços divergentes. Blocos de vida, expressão de Alan Pauls (2012), de uma "tribo em extinção" para Moreno, tal como sustenta em entrevista de novembro de 2016. Cito:

- Black out é o livro de memórias de uma tribo em extinção?

- Sim, considerando a extinção algo mais radical que a morte. O morto pode deixar um legado, ter-se reproduzido; o extinto, náo. Pode-se ler Black out junto com os diários de Ricardo Piglia (na verdade, de Emilio Renzi) e com Yo ya no (el don de la amistad), de María Pía López, retrato e tributo a Horacio González, como livros que conferem hospitalidade (é uma expressão de María Pía) ao que está sob ameaça. Eu sou mais pessimista e diria ao extinto. O extinto de um modo de intervir intelectual e político, de dialogar a partir da crítica com o poder, de ter como projeto

1 Uma primeira versão abreviada do texto foi apresentada no X Congresso Brasileiro de Hispanistas em Aracaju, 2018.

2 "Eles me impulsionaram a escrever este livro e são testemunhas das mesmas constelaçôes literárias”, declara Moreno (2016b) em entrevista concedida a Daniel Gigena. Salvo indicação contrária, a tradução ao português de todos os textos citados é minha. As referências aos originais em espanhol estão no final do ensaio. 
uma disrupção estética em relação ao establishment, de altercar com as mídias. Isso é o extinto (Moreno, 2016b).

Nas páginas que se seguem proponho examinar alguns fragmentos nos quais se póe em cena uma "imaginação intimista" (Link, 2007) ou, recorrendo às palavras de Renzi em seu diário, a "pré-história de uma imaginação pessoal” (Piglia, 2015, p.18), responsável por enformar essas poéticas idealizadas como lugar de "diálogo da crítica com o poder", de "disrupção estética", de altercação com as mídias, ainda que para isso se recorra, por exemplo, precisamente a um uso deslocado (Piglia) ou disparatado (Moreno) de uma mídia. Refiro-me à evocação da experiência de escutar rádio nos dias de infância e juventude por parte dos narradores de ambos os livros. Antes disso, porém, gostaria de comentar algumas passagens liminares de Black out.

Black out (Moreno, 2016a) se inicia com um relato breve (um caso, quase), protagonizado por um homem ébrio que sobe no ônibus carregando uma jaula enorme coberta por um pano. Ao desconforto geral e às recorrentes lamúrias do alcoólatra ("se perco esta jaula morro", ele diz) sucede um diálogo entre os passageiros:

Uma velha [...] perguntou o que levava na jaula. O homem respondeu: um mangusto. Não me separo dele porque sou bebum. Se não, quem vai comer as víboras? Um policial pergunta quais víboras. As do delirium 
tremens, respondeu. Mas essas víboras não são verdadeiras, disse uma moça [...]. Então, o homem levantou uma ponta do pano para mostrar que a jaula estava vazia. Tinha um ar radiante quando disse: mas este mangusto também não é verdadeiro! (Moreno, 2016a, p.10).

A anedota será vinculada de imediato a uma figuração do eu, "A primeira vez que ouvi esta história foi numa festa. Eu estava no quinto whisky" (Moreno, 2016a, p.11), e funcionará como emblema de um efeito de intensidade e de autenticidade altamente construídos. ${ }^{3}$ Do fundo dessa noite, da qual tudo terá sido esquecido, inclusive o caso do ébrio e do mangusto, emergirá uma recordação de infância: "Contra o fundo de tubos de ensaio pelos quais circulava algo em ebulição, minha mãe fazia uma mágica para mim” (Moreno, 2016a, p.12). À mãe química, que transmuta o álcool translúcido em líquido carmim, seguem-se as hemorragias da adolescência, a casa alugada no Delta, muitas décadas depois com Jorge Gumier Maier (que acabara de perder seu amante) e a repentina morte do próprio pai: "Então, morreu também meu pai” (Moreno, 2016a, p.15).

3 Veja-se a esse respeito mais um trecho da entrevista já citada:

"Gigena: No livro se faz referência à "carne de artista" e às intensidades biográficas, muito solicitadas hoje por editores e leitores.

Moreno: Creio que agora certas geraçóes que imaginam que a experiência da intensidade cessou (experiências como podem ter sido a militância da luta armada, a Aids, a liberação sexual) tendem a ler literalmente, como canibais de intensidade. Desfrutam do risco por delegaçáo. São como cafetôes de intensidade. E o livro é outra coisa. Na literatura, a intensidade é um efeito. Héctor Libertella escreveu em La arquitectura del fantasma que os alcoólatras amigos de Kerouac o consideravam um traidor da vida porque se embebedava com eles, mas a única coisa que pensava, na verdade, era sair correndo para escrever".

Para uma perspectiva solidária à de Moreno em relação à ênfase no caráter imaginário dessas intensidades biográficas cf. Link (2007). Para uma perspectiva polêmica, cf. Giordano (2008). 
Se me detive nesse incipit é porque aí comparece, pela primeira vez, neste livro (serão apontadas de imediato algumas ocorrências anteriores), a dicção que norteia a escrita de Moreno. Moreno envia uma amiga como emissária à cerimônia de enterro do pai enquanto aguarda "bebendo num bar em frente ao cemitério". Subitamente, o palavreado científico da progenitora, o luto pela perda paterna, o fantasma de Lamborghini e o humor (que nunca falta em sua escrita), se entrelaçam:

"Lisina = cadaverina. Diaminobutano ou butanodiamina = putrescina." Cada vez que morria um familiar querido e de idade avançada, minha mãe recitava os químicos da morte em longas párias parnasianas, para concluir com sua sentença: "Estava na idade de morrer". ${ }^{4}$<smiles>[AlH2]</smiles>

- Cadaverina e Putrescina como Soré e Resoré, divindades clancas da planura - eu disse [a minha amiga] recitando Osvaldo Lamborghini e ela me fez calar porque eu tinha falado quase cantando (Moreno, 2016a, p.1617)..$^{5}$

4 No original: modernistas, palavra que remete, como é sabido, aos pré-modernistas brasileiros e que opto por traduzir por "parnasianos" devido aos pontos de contato entre ambos os movimentos.

5 Osvaldo Lamborghini (Buenos Aires, 1940 - Barcelona, 1985). Poeta e prosista, autor de um conjunto de textos considerados entre as experimentaçóes mais radicais propostas nos anos de 1970. Seus escritos se caracterizam pelo cruzamento constante de registros linguísticos populares e autorreflexividade, referências a discursos teóricos de época (psicanálise, marxismo, etc.), sexualidade, violência física, beirando constante e propositadamente a ilegibilidade. Seu primeiro poema publicado, "Soré, Resoré", apareceu na revista Literal, no 1 (novembro de 
Retenho da passagem a tonalidade "parnasiana" de um dizer associado à figura materna (mas simultaneamente desviante em relação a ela), em vários outros momentos qualificado também como barroco, no qual convivem luxo (por vezes luxúria) verbal e opacidade, uma profusão linguística catada com frequência em zonas plebeias da vida social. Resgato, também, a deriva desse dizer em direção ao canto.

Combinatória análoga reaparece pouco mais tarde ao evocar o cortiço no qual transcorre a infância e adolescência, espaço aberto às contaminaçôes idiomáticas que tem um de seus núcleos fortes nos emigrados judeus residentes no bairro. Depois de referir os números tatuados no braço da senhora Seiden, "Doeu a tatuagem, senhora Ruth? - Não é uma tatuagem, chinfrinzinha, ${ }^{6}$ é meu número de telefone. Tenho má memória" (Moreno, 2016a , p.38), surge outra judia, Xenia Goldrosen, a dona do quiosque que fala sem parar:

- Treblinka, pais marieram, filhos marieram. Marido mariou. Primos, avós marieram. O que disse Xenia: Merda! Viver!

Sua pronunciaçấo associava a morte ao casamento. "Se marier", escutava eu, que tinha aulas particulares de francês $[\ldots]$. Um mundo quente de interrogaçôes me mostrava seres estranhos (Moreno, 2016a , p.39).

1973) e nele são invocadas essas duas "divindades clancas da planura". Clanco, termo inventado (dentre muitos outros) por Lamborghini, alude ao instável e não linear.

6 No original: chirusita, argentinismo que remete à mulher de comportamento vulgar. Frequentemente usado em letras de tango. 
Nesse universo, não estranha que de imediato irrompa o rádio, espaço privilegiado no que tange a contaminaçóes:

A circulação de diferentes [...] além da prosa de Emily Brontë traduzida ao rádio-teatro na voz de Pedro López Lagar, ${ }^{7}$ me ofereceu uma constelação que jamais associei com a tristeza, a discriminação e o genocídio, mas com a imaginação, a variedade e a mascarada [...]. Parecia-me natural que houvesse pessoas com telefones anotados nos braços, que os descamisados aludidos pelos discursos de Perón e Evita fossem uma multidão literalmente pelada, ${ }^{8}$ que as camisinhas usadas e jogadas fora na praça França fossem, como tinha me dito minha máe, protetores para os dedos que usavam os lixeiros para não lastimar-se com as garrafas quebradas que deixavam os bêbados. Minha ideia de povo excluía a luta política: era, ao invés disso, uma luta de línguas, de encenaçóes, de vestuários (Moreno, 2016a, p.4041).

Um modo de ouvir (uma escuta) origina um modo de ler/escrever (que é um dizer) na "pré-história da imaginaçáo pessoal" inventada pela escrita.

7 Pedro López Lagar (Madri, 1899 - Buenos Aires, 1977). Ator de longa trajetória na Argentina, onde se estabeleceu a partir de 1937. Muito popular por sua participaçáo em peças teatrais e especialmente em rádio-teatros. Também atuou no cinema.

8 Descamisados: denominação pejorativa das massas peronistas em alusão ao fato de marcharem, por vezes, em atos públicos, sem camisa e/ou camiseta, com o torço nu. Perón e Evita retomam e dignificam o termo em seus discursos endereçados ao povo. $\mathrm{O}$ enunciado "meus queridos descamisados" foi fórmula de endereçamento usual de muitos dos discursos de Eva Duarte. 
Referindo-se à primeira publicação das crônicas de Moreno em livro (trata-se de uma compilação de textos que apareceram nos anos $1980 \mathrm{em}$ diversos periódicos, reunidos em 2001 sob o título de $A$ tontas y a locas), María José Sabo (2015) destaca o papel chave da exumação desses materiais, geralmente tidos como menores pela crítica literária, postos a circular de forma disruptiva em outra temporalidade e outro suporte. Mas essa volta aos próprios materiais, longe de instituir uma relação com o passado entendida como restituição, sutura, unidade ou coerência da obra, busca "o abalo desses valores, reafirmando precisamente as potências da instabilidade e a fragmentaçáo dos materiais convocados a partir da abertura do arquivo" afirma Sabo (2015, p.69). A observação vale para Black out e também para os Diarios de Emilio Renzi, o que conduziria a uma discussão sobre o papel do fragmento e as interferências temporais nesses escritos, uma questão da qual tentei me aproximar em outro ensaio, mas que não será tratada aqui. ${ }^{9}$ Outro aspecto em comum ainda, vinculado ao precedente, relaciona-se com o constante trabalho de "reciclagem" empreendido por Moreno desde então, ao qual ela tem se referido com frequência como "autoplágio" - um procedimento que qualquer leitor familiarizado com a produção de Piglia não terá dificuldade em identificar. Mas o que interessa retomar neste momento é a defesa por parte da Moreno, cronista de uma dicção lateral, enviesada, de um modo de dizer que, conforme Sabo

9 Cf. Gárate (2018). 
(2015, p.70), reivindica "os espaços de enunciação marginais, esquivos ao dogma... distantes do púlpito e do estrado" - eis um contraste com um tom que não é incomum nos escritos de Renzi/Piglia, frequentados por sentenças e aforismos. Definidas pela própria Moreno como uma "gritaria na intempérie", as crônicas de $A$ tontas y a locas se vinculam a formas de protesto social e enfatizam - novamente cito Sabo (2015, p.71) - "a forte marca de oralidade que impregna a escrita da autora que, em mais de uma ocasião, confessou ter sido modelada pela rádio”.

A (auto)figuração desse modelado, dessa afiliação ${ }^{10}$ a uma escrita que é um dizer e uma leitura que é um ouvir, comparece em mais de um dos ensaios reunidos em Subrayados: leer hasta que la muerte nos separe, de 2013. ${ }^{11}$ No início de "Y todo así", por exemplo, se afirma:

Vou escrever sobre literatura universal, quer dizer, sobre tango. $\mathrm{Na}$ adolescência "a fama" era para mim que toda caneta se chamasse Bic, toda lâmina de raspar Gilette mas, acima de tudo, que numa letra de Cadícamo, Darío fosse chamado só pelo nome. $\mathrm{O}$ tango-canção foi minha primeira "leitura". Ouvia-o, mesmo sem querer, no rádio que a empregada escutava a todo volume [...]. A empregada, fã de La hora de las ofertas e do Glostora tango club, iniciava-me no gosto pela metáfora. Que belo isso de "a

10 Para a distinção filiação/afiliação, cf. Said (2004).

11 Segundo informação constante na última página do livro, a maior parte dos ensaios foi originariamente publicada na revista Debate e no jornal Página/12. 
serpentina nervosa e fina" [...]. Mais tarde, não o ouvido mas o péssimo ouvido levou-me ao surrealismo (Moreno, 2013c, p.99). ${ }^{12}$

A conclusão desse texto poderia ser o início de outro, do mesmo livro, que leva o título de "Gardel": "Meu primeiro sublinhado foi de ouvido" (Moreno, 2013a, p.57), frase inaugural que abre caminho à rememoração do período de surmenage adolescente no qual a narradora abandona a escola e passa os dias trancada no quarto, ouvindo pelo rádio o programa El bronce que sonrie, de Julio Jorge Nelson. ${ }^{13}$ Como se desenhasse círculos, esse texto conclui por sua vez com este enunciado: "Seguindo as linhas de Gardel com os ouvidos e agarrada ao tango-canção, fui dar na poesia parnasiana e na literatura abarcável, [...] poderia dizer que com Gardel aprendi a ler" (2013a, p.63, grifo da autora). Daí o "gosto pelos livros que fingem a transcrição de uma voz". A frase é de outro ensaio de Subrayados, "La ponchera está en orden” (2013c, p.231), e acredito que Renzi não teria o menor problema em endossá-la, como atestam os inúmeros fragmentos dos Diarios (especialmente volumes um e dois) que tematizam a busca de um registro (escrito) capaz de simular um efeito de

12 O título do ensaio de Moreno ("Y todo asî") cita um dos versos do tango En harapos (em farrapos), que teria sido escrito pelo poeta anarquista Alberto Ghiraldo, foi musicado por Marino García e gravado em disco em 1927. No original em espanhol Moreno recorre a um eufemismo usual entre os setores de classe média para referir-se à empregada doméstica, muchacha (moça), em torno ao qual tece consideraçóes irônicas. O Darío da citaçáo é, evidentemente, o poeta Rubén Darío.

13 Pseudônimo de Julio Isaac Rosofsky (Buenos Aires, 1913 - 1976), escritor de letras de tangos, ator e apresentador de rádio. Pouco depois da morte de Gardel, deu início ao programa El bronce que sonríe, integralmente dedicado ao cantor e de enorme sucesso durante décadas. 
oralidade, dando continuidade a uma preocupação já registrada em ficçóes críticas precedentes que adotam a forma do diário (vejam-se, por exemplo, "Notas sobre literatura en un Diario", de 1984 e "Notas sobre Macedonio en un Diario", de 1985). Tampouco Piglia, que tratou dessa questão em numerosos artigos e nas aulas ministradas em 1990, posteriormente publicadas na forma de livro sob o título de Las tres vanguardias (Piglia, 2016).

II

Outro texto de Moreno, primeiramente publicado na imprensa cotidiana e recolhido em Subrayados, vai me servir como passagem (ou como passe de mágica, talvez). O episódio é conhecido: em 1997 Piglia ganha o Prêmio Planeta e é processado por Gustavo Nielsen sob alegaçáo de contatos prévios com a editora, que teriam fraudado o anonimato do concurso (em 2003 será a vez do processo movido por Blanca Rosa Galeano, e, em 2008, por Claudia Dorda). "De concurso" se posiciona em relação à contenda e a favor de Piglia, alertando para a "juridicofilia" que teria avançado também no âmbito da literatura. Mas o juízo expresso no início desloca a conflagração para outra cena e instaura sub-repticiamente outro tipo de controvérsia:

Não sou devota da obra de Ricardo Piglia embora admito suas qualidades. Li salteado Borges, Joyce, Faulkner. Larguei-os sem nostalgia. Dirão que, ao colocar Piglia em minha série do valorado sem afeto, coloco-o de qualquer forma nas alturas. Acontece que o que não valoro são as alturas, 
prefiro leituras menos evidentes, mais caprichosas (Moreno, 2013b, p.69, destaque da autora).

Não vou me deter neste trabalho no que pode ser lido como uma deriva do escrito de Moreno em direção a um afeto (a um valor) indissociável de certo "rebaixamento". Mas considero que o malicioso e cordial retrato de Piglia como "professor" (embora a caracterização o exceda) ${ }^{14}$ e, sobretudo, o modo de traduzir/imaginar a contenda jurídica à maneira de um conto de Miguel Briante (um dos parceiros incontornáveis da "Passarela do álcool" em Black out,$^{15}$ um duplo ou assombração nas anotaçôes do jovem Renzi

14 Cito:

"Com frequência tem se insultado Piglia com a simples marcação de seu ofício: "professor". $\mathrm{Na}$ Argentina, o intelectual, ainda que receba uma herança, continua sendo professor. É o homem da pasta surrada que, nas estradas argentinas, costuma descansar de seu Benjamin ou de seu Jauretche com a cabeça ricocheteando contra a janela do ônibus, rumo à Universidade de Tucumán ou de Rosario, onde dará intermináveis horas de aula antes de voltar a ser de novo tração a sangue em alguma universidade local. Vetusto continuará prestando concursos devido ao sistema. Sem ter se proposto seguir o modelo ascético de um Alfredo Palacios, costuma aceder à casa própria passados os cinquenta anos e a bolsa Guggenheim, mais do que bancar a grande obra nacional, costuma ajudá-lo no pagamento do condomínio ou do plano de saúde. Se trabalha fora do país, vive melhor, mas não trabalha menos e é provável que não lhe sobre tempo para viver melhor" (Moreno, 2013b, p.71-72, destaque da autora).

15 "A passarela do álcool" é o título de uma das três partes que integram Black out e à qual a autora se refere nos seguintes termos na última página do livro:

"Imaginei este livro como um tributo múltiplo e ritual de despedida sem nenhum resquício para a nostalgia - só se tem nostalgia do que náo foi vivido. Dividido em três partes que se repetem, cada uma delas responde a uma ordem diferente. A passarela do álcool, à do retrato; Do outro lado da porta vai-vem, à do microensaio; Ronda, à do território" (Moreno, 2016, p.407). Os sete fragmentos intitulados "A passarela do álcool", que alternam com os das as outras duas partes, evocam pessoas decisivas em termos afetivos, intelectuais e de formaçáo vinculadas, ademais, pelo comum consumo do álcool: Alcides Zubarán (um vizinho de infância e 
dos anos 1960-1970) podem ser vistos como gestos que acenam nessa direção. Transformar o pleito de Piglia em um conto de "pueblo chico", em uma carreira na qual disputa o cavalo do comissário, impingir uma boa dose de humor sem prejuízo da sofisticação, é trazer Piglia para perto da própria zona. ${ }^{16}$ Trata-se de uma operação empreendida por Moreno em vários artigos publicados nos anos 2000, tais como "Che lector", por exemplo, no qual resgata a associação estabelecida por Piglia entre Mansilla, Victoria Ocampo e o Che "devido ao uso de uma língua que simula, em sua naturalidade inventada, um efeito oral" (Moreno, 2013d, p.258). Ou em "Puig con Walsh", no qual sublinha o uso do gravador por parte de ambos como dispositivo tecnológico que possibilita ouvir (reinventar) modos de dizer. $\mathrm{O}$ paulatino encontro que se processa nesses textos culmina no endereçamento de Black out ("a Beba Eguía e Ricardo Piglia") e, mais recentemente, em Oración: carta a Vicki y otras elegias políticas, livro de 2018 no qual Moreno retoma e referenda a leitura proposta por Piglia da carta homônima de Walsh à filha morta. ${ }^{17}$

puberdade), os jornalistas e os escritores Norberto Soares, Miguel Briante, Jorge di Paola Levín, Charlie Feiling e o artista plástico Jorge Gumier Maier.

16 "Plata quemada é um grande romance. Imaginemos um conto de Miguel Briante. Uma corrida num pueblo chico. Os jockeys estáo comprados. Porque corre o cavalo do comissário. Depois da largada, para que seja mais verossímil, todos saem disparados, e antes de começar a minguar a marcha, veem que o cavalo do comissário leva três cabeças de vantagem ao que está na frente. Os que iriam fingir perder, perderam realmente. O que Nielsen não se resigna a entender é que às vezes ganha o cavalo do comissário sem que a trapaça haja sequer podido ser tentada" (Moreno, 2013b, p.72).

17 Cf. Piglia (2001), “Tres propuestas para el próximo milenio y cinco dificultades”. No apartado que leva o título de "Verdad de la ficción", um dos últimos de Oración, lê-se: "Ricardo Piglia 
Em "Rumores vecinales", Horacio González (2017) propóe uma instigante reflexão sobre as relações instauradas entre literatura e vida ou narração e experiência nos Diarios de Emilio Renzi - alter-ego que, como é sabido, percorre a produção de Piglia, e cujas implicaçóes se complexificam em função do estatuto supostamente autobiográfico dos diários, como assinala Martín Kohan (2017) em outro interessante artigo. As consideraçôes de Kohan em torno dessa "secundariedade nominal" convidam a pensar sob um prisma parcialmente análogo à produçáo de María Moreno, alter-ego mais assíduo de Cristina Forero, embora Forero/Moreno também tenha publicado colunas jornalísticas com um heterônimo masculino (Juan González Carvalo), outro de anciã (Rosita Falcón) e produzido os supostos manuscritos de Skeffington em El affair Skeffington (1992). Também no caso de Black out, a emergência de um texto situado no liminar do autobiográfico (não obstante a precaução sobre o caráter não verdadeiro do mangusto) complexifica as relaçôes entre o alter-ego e o eu que se torna outro. Apontada a questão, que deixo em aberto, retomo o fio condutor desta leitura e volto ao texto de González,

escreveu sobre Carta a Vicki: "Talvez o soldado nunca existiu, como talvez nunca existiu o homem no trem, o que conta é que estão aí para poder narrar o ponto cego da experiência. Pode ser entendido como uma ficção; tem, evidentemente, a forma de uma ficção destinada a dizer a verdade; o relato se desloca a uma situação concreta na qual há um outro, inesquecível, que permite fixar e tornar visível o que se quer dizer"” (Moreno, 2018, p.365-6). Registro a necessidade de explorar Oración a partir de um signo contrário, objetivo que excede os limites desta leitura: seria preciso examinar nesse último livro de Moreno os deslocamentos sistemáticos da voz e da autoridade das interpretaçóes masculinas, bem como o amaranhado de vozes femininas que se acolhe e faz reverberar no texto. 
que parte da recuperação de um episódio preciso: a direção conjunta de Ricardo Piglia e Sergio Camarda, em finais de 1965, daquele que seria o único número publicado da revista Literatura y sociedad.

Nos Diarios de Piglia, Literatura y sociedad é mencionada várias vezes. A mais importante dentre elas é a indicaçấo de que a verdadeira tarefa era refletir sobre esse "e" conectivo. Mas seria constatado, com o passar do tempo, que a reflexáo sobre o conectivo deveria ceder o passo náo a uma interpretação mais sugestiva do "e", mas à sua drástica supressão como problema. O oblíquo e a elipse seriam modulações de substituição (González, 2017, p.393).

González frisa que nesse número único Piglia escreve como um jovem da nova esquerda e, em consonância com esta, propóe superar a "falsa consciência" que afetaria a esquerda tradicional. No entanto, precocemente, ele teria ensaiado imprimir outra forma a uma questão que não desaparece, mas passa a ser meditada a partir da ausência, da distância ou do hiato. A supressão de nexos, a proliferação de subentendidos e o uso da elipse tornam-se um modo de "resguardar revelações, mas também de fazêlas por meio de signos oblíquos e encobertos" (González, 2017, p.394). Ao longo desse trajeto, do qual González retira preventivamente toda homogeneidade ou direção linear:

a literatura não fica "sem" a "sociedade", mas como uma forma evocativa, uma distância que apenas reverbera trazendo ecos de um objetivismo perdido. Essa perda não aniquila o mundo objetivo, torna esse mundo 
um modo da distância, faz com que se manifeste como um eco, que póe o escritor à escuta de um rádio de galena cujo som chega aleatoriamente, e se interrompe com frequência (González, 2017, p.396).

Sob um signo diferente do de Moreno, mas acenando para uma sensibilidade de época comum ao trio que ela compóe com Renzi/Piglia e com González, surge outra vez "a escuta do rádio de galena” como possível figuração de uma poética.

Cito dois fragmentos de Los Diarios de Emilio Renzi, um datado de 1960 e o outro de 1968:

Escuto a partida de futebol no rádio (Independiente $2 \times 0$ Boca), uma narração que acompanhou, como uma música distante, os domingos da minha infância. Há uma irrealidade verbal na narração de açóes que não vemos e devemos imaginar. Interessa-me o fato de ela ser acompanhada pelos "comentários", quer dizer, pela explicação teórica do que acontece no jogo. A narração e o conceito que a define vêm juntos (Piglia, 2015, p.95).

Experiência narrativa do boxe. Descrição verbal que se movimenta em três planos: narração rápida do que vai ocorrendo, uma análise lúcida da técnica e da estratégia da luta e, por fim, os gritos que se filtram desde o ringue e a plateia. Seria preciso escrever um romance que operasse com os dois primeiros níveis: narração e análise em um só relato. Isto vem à baila porque escuto [no rádio] a narração da luta entre Bonavena e Foley, que 
tem momentos de irônica picardia: "Bonavena olhou para a plateia e seu rival se enfureceu." (Piglia, 2016, 43)

Menos que a uma dicção (isto é, que a um efeito de oralidade pelo qual Renzi/Piglia também se interessam, mas que eles "ouvem” na escrita de Macedonio ou de Arlt), o rádio remete, neste caso, a um modo (duplo) de estruturação do discurso. A "narração rápida do que vai ocorrendo", "de açóes que não vemos e devemos imaginar”, aponta em direção a uma de suas linhas de força: o relato trunco, lacunar, a elipse. A "análise da técnica e da estratégia”, “o comentário do que acontece no jogo”, em direção à outra. Operando com os dois níveis em revezamento constante dá-se forma a esse modo de "pensar enquanto se narra", de interferir e interromper a suposta fluidez natural do relato, que Pauls (2017) assinalou como marca indelével dos escritos de Piglia. As cenas em que a imaginação intimista de Renzi se autofigura ouvindo rádio evocam a pré-história dessa poética na qual "a literatura não fica sem a sociedade”, mas se torna uma forma evocativa, uma distância que apenas reverbera trazendo ecos de um objetivismo perdido. Essa perda não aniquila o mundo objetivo, torna esse mundo um modo da distância, faz com que se manifeste como um eco que póe o escritor à escuta de um rádio de galena cujo som chega aleatoriamente, $\mathrm{e}$ se interrompe com frequência." (González, 2017). Memórias de uma tribo em extinção. 


\section{REEERÊNCIAS BIBLIOGRÁFICAS}

Gárate, Miriam V. "Notas de trabalho: a propósito de Los diarios de Emilio Renzi”. In: Ferraz, Eduardo e Pimentel, Júlio (org.). Só se perde o que realmente não se teve: leituras e diálogos com Ricardo Piglia. Rio de Janeiro: Estudos Americanos, 2019, p.221-245.

Giordano, Alberto. "El giro intimista. Las confesiones de Daniel Link". In: Boletin del Centro de Estudios de Teoría y Crítica Literaria, 13-14, 2008, p.1-9. Disponível em: https://bit.ly/2HZAOaK. Acesso em 15 jun. 2018.

González, Horacio. "Rumores vecinales”. In: Revista Landa, p.5-2, 2017, p.392406. Disponível em: https://bit.ly/2V3D4RL. Acesso em 4 out. 2017.

Kohan, Martín. "Alter ego. Ricardo Piglia y Emilio Renzi: su diario personal”. In: Revista Landa, p.5-2, 2017, p.261-272. Disponível em: https://bit. ly/2YuMGqZ. Acesso em 4 out. 2017.

Link, Daniel. . “La imaginación intimista” Disponível em: http://linkillo.blogspot. com/2007/08/la-imaginacion-intimista.html Acesso em 4 ag. 2017.Moreno, María. "Gardel". In: Subrayados: leer hasta que la muerte nos separe. Buenos Aires: Mardulce, 2013a, p.57-64.

."De concurso". In: Subrayados: leer hasta que la muerte nos separe. Buenos Aires: Mardulce, 2013b, p.69-73.

. "Y todo así". In: Subrayados: leer hasta que la muerte nos separe. Buenos Aires: Mardulce, 2013c, p.99-101.

. “La ponchera está en orden”. In: Subrayados: leer hasta que la muerte nos separe. Buenos Aires: Mardulce, 2013d, p.231-234.

. "Che lector". In: Subrayados: leer hasta que la muerte nos separe. Buenos Aires: Mardulce, 2013e, p.255-270.

. "Puig con Walsh". In: Subrayados: leer hasta que la muerte nos separe.

Buenos Aires: Mardulce, 2013f, 271-282.

. Black out. Buenos Aires: Random House, $2016 \mathrm{a}$. 
Moreno, María. "La escritura plebeya, la mía, es la que se escribe en contaminación". La Nación, Buenos Aires, 24 nov. 2016b. Entrevista concedida a Daniel Gigena. Disponível em: https://bit.ly/2CLt0FZ. Acesso em 8 abr. 2018.

. Oración: carta a Vicki y otras elegías políticas. Buenos Aires: Random House, 2018.

Pauls, Alan. Temas Lentos. Santiago: Universidad Diego Portales, 2012.

Piglia, Ricardo. "Tres propuestas para el próximo milenio (y cinco dificultades)". In: Casa de las Américas, 222, 2001, p.11-21.

. Los diarios de Emilio Renzi: años de formación. Barcelona: Anagrama, 2015. (Los diarios de Emilio Renzi, v. 1). . Los diarios de Emilio Renzi: los años felices. Barcelona: Anagrama, 2016. (Los diarios de Emilio Renzi, v. 2). . Los diarios de Emilio Renzi: los años felices. Barcelona: Anagrama, 2017. (Los diarios de Emilio Renzi, v. 3).

. Las tres vanguardias: Saer, Puig, Walsh. Buenos Aires: Eterna Cadencia, 2016.

Sabo, María José. "Porque no habrá obra. El archivo en la escritura de María Moreno". In: Orbis Tertius, 20-22, 2015, p.68-79. Disponível em: https://bit. ly/2HWtJaC. Acesso em 23 jun. 2018.

Said, Edward. El mundo, el texto y el crítico. Buenos Aires: Debate, 2004. 